Case Reports in
Gastroenterology
Case Rep Gastroenterol 2021;15:418-423

DOI: 10.1159/000514892

Published online: April 6, 2021
(C) 2021 The Author(s)

Published by S. Karger AG, Base www.karger.com/crg

This article is licensed under the Creative Commons Attribution-NonCommercial 4.0 International License (CC BY-NC) (http://www.karger.com/Services/OpenAccessLicense). Usage and distribution for commercial purposes requires written permission.

\title{
Abdominal Ascites of Unknown Origin: Diagnostic Accuracy of Adenosine Deaminase for Tuberculous Peritonitis
}

\author{
Shehriyar Mehershahi ${ }^{a}$ b Asim Haider $^{b} \quad$ Ked Fortuzi $^{b}$ \\ Danial H. Shaikh ${ }^{a}$ barish Patel ${ }^{a, b}$ \\ aGastroenterology, BronxCare Health System, Bronx, NY, USA; bInternal Medicine, \\ BronxCare Health System, Bronx, NY, USA
}

\section{Keywords}

Abdominal pain · Adenosine deaminase $\cdot$ Ascites · Liver

\begin{abstract}
The occurrence of tuberculosis (TB) is exceedingly rare in the United States (US), and incidence has steadily declined since 1993 , but the pace of decline has slowed in recent years. The US TB rate during 2019 declined to 2.7 cases per 100,000 persons, the lowest level on record. The abdominal form is the sixth leading cause of extrapulmonary TB, after lymphatic, genitourinary, osteoarticular, miliary, and meningeal. Abdominal TB can infect any part of the gastrointestinal tract, including the peritoneum and the pancreaticobiliary system. We present a case of persistently elevated adenosine deaminase in peritoneal ascites of a young, healthy female with new-onset ascites. An extended diagnostic evaluation was performed to reach the diagnosis.

\section{Introduction}

Abdominal tuberculosis (TB) is predominant in individuals $<40$ years of age, with a higher frequency in females [1]. The risk factors for developing peritoneal TB are HIV infection,

$\begin{array}{ll} & \text { Shehriyar Mehershahi } \\ \text { Department of Gastroenterology } \\ \text { BronxCare Health System } \\ 1650 \text { Grand Concourse, Bronx, NY } 10457 \text { (USA) } \\ \text { smehersh@bronxcare.org }\end{array}$




\section{Case Reports in Gastroenterology}

Case Rep Gastroenterol 2021;15:418-423

DOI: $10.1159 / 000514892$

(c) 2021 The Author(s). Published by S. Karger AG, Basel www.karger.com/crg

Mehershahi et al: Abdominal Ascites of Unknown Origin: Diagnostic Accuracy of Adenosine Deaminase for Tuberculous Peritonitis

cirrhosis, diabetes, malignancy, and receiving continuous ambulatory peritoneal dialysis [2]. The clinical presentation can be acute or chronically intermittent. Most patients (80-95\%) have abdominal pain, $40-90 \%$ fever, $11-20 \%$ diarrhea and constipation, and $40-90 \%$ weight loss, anorexia, and malaise [3]. Peritoneal TB occurs in 3 forms: (a) wet type with ascites, (b) dry type with adhesions, (c) fibrotic type with omental thickening, and loculated ascites [3]. Patients with peritoneal TB manifest a slowly progressive abdominal swelling from ascites and abdominal pain. Approximately $90 \%$ of patients with TB peritonitis suffer from ascites [4]. Pathogenesis involves infection by tubercle bacilli (a) following reactivation via hematogenous spread from a primary lung focus, (b) via hematogenous spread from active pulmonary or miliary TB, and (c) through lymph channels from infected nodes. Peritoneal involvement may occur from infected contiguous lymph nodes, intestinal lesions, or fallopian tubes in women. Additionally, abdominal lymph nodal and peritoneal TB may develop without gastrointestinal involvement in $30 \%$ of cases [2].

\section{Case Presentation}

We are reporting a 32-year-old woman known to have diabetes mellitus who presented to the emergency department initially with a 2-week history of abdominal distention and increased abdominal girth associated with shortness of breath. She denied any nausea, vomiting, abdominal pain, loss of appetite, early satiety or unintentional weight loss, hematemesis, melena, or hematochezia. The patient denied any past surgical history. She was born and raised in the USA and never traveled outside the USA. Her social history was significant for active tobacco and marijuana smoking. She had no known allergies. Her initial vitals were blood pressure of $131 / 79 \mathrm{~mm} \mathrm{Hg}$, a pulse of $83 \mathrm{bpm}$, respiratory rate of 18 , and temperature of $98.6^{\circ} \mathrm{F}$. On examination, the abdomen was soft and distended with positive shifting dullness. Bowel sounds were normal.

Computed tomography (CT) scan of the abdomen and pelvis with contrast showed a large amount of ascites with normal hepatic architecture. Ultrasound of the pelvis showed largevolume ascites and normal appearing ovaries and uterus. The patient underwent paracentesis showing a low SAAG value (of 1 and repeat 0.6 ) with high protein (6.4 and repeat 7), neutrophilic predominance initially (total WBCs 6,760 with 95\% neutrophils), then lymphocytic predominance (total WBCs 3,840 with $64 \%$ lymphocytes); cytology of ascitic fluid was negative for any malignant cells. Of note, she was found to have an adenosine deaminase (ADA) level of 113 in ascitic fluid; upon repeat testing, the level was 100.6. Acid-fast staining, MTB PCR, and mycobacterium cultures were negative in ascitic fluid. Ascitic fluid amylase level was $46 \mathrm{U} / \mathrm{L}$, TAG level was $22 \mathrm{mg} / \mathrm{dL}$, and LDH level was $554 \mathrm{U} / \mathrm{L}$. HIV testing, HCV testing, HAV IgM, and auto-immune workup, including ANA, ANCA vasculitis antibodies, anti-smooth muscle antibodies, and liver kidney microsomal antibodies, were also negative. Serum pro-BNP was 40 $\mathrm{pg} / \mathrm{mL}$, lipase $37 \mathrm{U} / \mathrm{L}$, ceruloplasmin level $38 \mathrm{mg} / \mathrm{dL}$, alpha-1-antitrypsin level $144 \mathrm{mg} / \mathrm{dL}$, ESR $100 \mathrm{~mm} / \mathrm{h}$, and CRP was $85 \mathrm{mg} / \mathrm{L}$. Her serum immunofixation showed a dense polyclonal pattern suggestive of chronic inflammation. Urine testing for Chlamydia trachomatis and Neisseria gonorrhoeae was negative. CT of the chest and CT of the abdomen and pelvis with contrast material were negative for any malignant focus. She underwent exploratory abdominal laparoscopy, which revealed fibrinous exudate on the peritoneal surface, and had a biopsy of the peritoneum. The pathology report from the peritoneal biopsy showed granulomatous inflammation with no malignancy (Fig. 1). PAP smear showed atypical squamous cells of

\section{Karger'=}




\section{Case Reports in Gastroenterology}

Case Rep Gastroenterol 2021;15:418-423

DOI: 10.1159/000514892

(c) 2021 The Author(s). Published by S. Karger AG, Basel www.karger.com/crg

Mehershahi et al.: Abdominal Ascites of Unknown Origin: Diagnostic Accuracy of Adenosine Deaminase for Tuberculous Peritonitis

undetermined significance. Endometrial biopsy was also negative for any malignancy. Transvaginal ultrasound showed normal ovaries. She also had EGD and colonoscopy to rule out gastrointestinal malignancy and in view of the unknown origin of ascites. EGD and colonoscopy both were unremarkable, and biopsy reports were negative for any malignancy. The patient was lost to follow-up, and treatment was not initiated.

\section{Case Discussion}

An abdominal TB diagnosis can be challenging, especially for the peritoneal type, because the signs and symptoms are often very subtle. The differential diagnosis of peritoneal TB should be kept in mind in patients presenting with nonspecific symptoms of nausea, vomiting, and fever associated with ascites [4].

Ascitic fluid analysis is routinely performed in evaluating all patients presenting with ascites. The WBC in peritoneal TB varies widely, ranging from counts of $<100$ cells $/ \mathrm{mm}^{3}$ to as high as 5,000 cells $/ \mathrm{mm}^{3}$ [5]. The cells are predominantly lymphocytes. For unknown reasons, patients on peritoneal dialysis with tuberculous peritonitis may have a neutrophilic response [5]. The ascitic fluid protein content is usually $>3.0 \mathrm{~g} / \mathrm{dL}$ in the setting of tuberculous peritonitis [6]. Patients with tuberculous peritonitis (in the absence of underlying cirrhosis) typically have SAAG $<1.1 \mathrm{~g} / \mathrm{dL}$; patients with underlying cirrhosis have $S A A G \geq 1.1[2,7]$. The sensitivity of AFB smear and mycobacterial culture of ascites fluid is low $(<2$ and $<20 \%$, respectively) [8].

Measurement of ascitic fluid ADA levels can be a useful diagnostic tool for the diagnosis of TB peritonitis. Its diagnostic reliability increases in the absence of cirrhosis [9]. A metaanalysis study, including 264 patients, found that ADA levels had high sensitivity (100\%) and specificity (97\%) using cutoff values from 36 to 40 IU/L [10]. The sensitivity of ascites fluid ADA in patients with cirrhosis is approximately $30 \%$. This low sensitivity is attributed to inadequate humoral and T-cell-mediated responses [7]. It is recommended to use lower thresholds (21-30 IU/L) in such cases [11,12].

Obtaining biopsy specimens from the peritoneum is another diagnostic modality that can be used to diagnose TB peritonitis. In one systematic review, including 402 patients, the sensitivity and specificity of laparoscopic examination in making the diagnosis of peritoneal TB was 93 and 98\%, respectively [2]. Gross laparoscopic findings expected in tuberculous peritonitis are (1) thickened peritoneum with yellow/white lesions with or without adhesions, (2) thickened peritoneum with or without adhesions, and (3) fibroadhesive pattern [13, 14]. Biopsy specimens should be sent for microbiological evaluation, including AFB smear, mycobacterial cultures, and PCR as well as histopathological evaluation. The sensitivity of AFB smear and mycobacterial culture for biopsy specimens is low $(<50 \%)[15,16]$. If available, PCR is more sensitive and specific for the diagnosis of TB than AFB smear or mycobacterial culture, and often PCR results are available sooner $[17,18]$. The presence of caseating granulomas is suggestive of TB but is not pathognomonic. Ascitic fluid ADA levels, along with clinical and epidemiological factors, can help establish a diagnosis under such circumstances.

Finally, it may not be possible to establish a definitive diagnosis of abdominal TB. For situations in which there is a high index of suspicion based on clinical, epidemiologic, and diagnostic findings (such as elevated ascitic fluid ADA and consistent findings in histology, with nondiagnostic mycobacterial culture), an empiric trial of antituberculous therapy is

\section{Karger'=}


reasonable. In general, the approach to antituberculous therapy for peritoneal TB is the same as for pulmonary TB $[19,20]$.

Measurement of ascitic fluid ADA levels is a valuable diagnostic tool for the diagnosis of TB peritonitis. ADA sensitivity and specificity increases in the absence of cirrhosis. After exhausting all the common and rare causes of new-onset ascites, our patient was found to have a persistent elevation of ADA. The patient had no underlying liver disease. Even though acidfast staining, mycobacterial culturing, and PCR may be negative, it should not deter the physician from further evaluation and empirical treatment for TB.

\section{Acknowledgement}

This article does not include any non-author contributors to acknowledge.

\section{Statement of Ethics}

Written informed consent was obtained from the patient for publication of this case report and any accompanying images.

\section{Conflict of Interest Statement}

The authors of this article do not have any conflict of interest to declare.

\section{Funding Sources}

This article did not receive any funding.

\section{Author Contributions}

All authors certify that he or she has participated sufficiently in the intellectual content and the analysis of data. Each author has reviewed the final version of the manuscript and approves it for publication. Should the editors request the data upon which the work is based, the authors shall produce it.

\section{References}

1 Bhatia MS, Srivastava S, Sharma S. 1. An uncommon case of zoophilia: a case report. Med Sci Law. 2005 Apr;45(2):174-5.

2 Sanai FM, Bzeizi KI. Systematic review: tuberculous peritonitis-presenting features, diagnostic strategies and treatment. Aliment Pharmacol Ther. 2005 Oct;22(8):685-700.

3 Sharma MP, Bhatia V. Abdominal tuberculosis. Indian J Med Res. 2004 Oct;120(4):305-15.

4 Khan R, Abid S, Jafri W, Abbas Z, Hameed K, Ahmad Z. Diagnostic dilemma of abdominal tuberculosis in nonHIV patients: an ongoing challenge for physicians. World J Gastroenterol. 2006 Oct;12(39):6371-5.

\section{Karger'=}




\section{Case Reports in Gastroenterology}

\begin{tabular}{l|l}
\hline Case Rep Gastroenterol 2021;15:418-423 \\
\hline DOI: 10.1159/000514892 & $\begin{array}{l}\text { @ 2021 The Author(s). Published by S. Karger AG, Basel } \\
\text { www.karger.com/crg }\end{array}$ \\
\hline
\end{tabular}

Mehershahi et al.: Abdominal Ascites of Unknown Origin: Diagnostic Accuracy of Adenosine Deaminase for Tuberculous Peritonitis

5 Lui SL, Tang S, Li FK, Choy BY, Chan TM, Lo WK, et al. Tuberculosis infection in Chinese patients undergoing continuous ambulatory peritoneal dialysis. Am J Kidney Dis. 2001 Nov;38(5):1055-60.

6 Kim NJ, Choo EJ, Kwak YG, Lee SO, Choi SH, Woo JH, et al. Tuberculous peritonitis in cirrhotic patients: comparison of spontaneous bacterial peritonitis caused by Escherichia coli with tuberculous peritonitis. Scand J Infect Dis. 2009;41(11-12):852-6.

7 Hillebrand DJ, Runyon BA, Yasmineh WG, Rynders GP. Ascitic fluid adenosine deaminase insensitivity in detecting tuberculous peritonitis in the United States. Hepatology. 1996 Dec;24(6):1408-12.

8 Marshall JB. Tuberculosis of the gastrointestinal tract and peritoneum. Am J Gastroenterol. 1993 Jul;88(7):989-99.

9 Lewinsohn DM, Leonard MK, LoBue PA, Cohn DL, Daley CL, Desmond E, et al. Official American Thoracic Society/Infectious Diseases Society of America/Centers for Disease Control and Prevention Clinical Practice Guidelines: Diagnosis of Tuberculosis in Adults and Children. Clin Infect Dis. 2017 Jan;64(2):e1-33.

10 Riquelme A, Calvo M, Salech F, Valderrama S, Pattillo A, Arellano M, et al. Value of adenosine deaminase (ADA) in ascitic fluid for the diagnosis of tuberculous peritonitis: a meta-analysis. J Clin Gastroenterol. 2006 Sep;40(8):705-10.

11 Rathi P, Gambhire P. Abdominal Tuberculosis. J Assoc Physicians India. 2016 Feb;64(2):38-47.

12 Liao YJ, Wu CY, Lee SW, Lee CL, Yang SS, Chang CS, et al. Adenosine deaminase activity in tuberculous peritonitis among patients with underlying liver cirrhosis. World J Gastroenterol. 2012 Oct;18(37):5260-5.

13 Bhargava DK, Shriniwas, Chopra P, Nijhawan S, Dasarathy S, Kushwaha AK. Peritoneal tuberculosis: laparoscopic patterns and its diagnostic accuracy. Am J Gastroenterol. 1992 Jan;87(1):109-12.

14 Uzunkoy A, Harma M, Harma M. Diagnosis of abdominal tuberculosis: experience from 11 cases and review of the literature. World J Gastroenterol. 2004 Dec;10(24):3647-9.

15 Hickey AJ, Gounder L, Moosa MY, Drain PK. A systematic review of hepatic tuberculosis with considerations in human immunodeficiency virus co-infection. BMC Infect Dis. 2015 May;15:209.

16 Diaz ML, Herrera T, Lopez-Vidal Y, Calva JJ, Hernandez R, Palacios GR, et al. Polymerase chain reaction for the detection of Mycobacterium tuberculosis DNA in tissue and assessment of its utility in the diagnosis of hepatic granulomas. J Lab Clin Med. 1996 Apr;127(4):359-63.

17 Donoghue HD, Holton J. Intestinal tuberculosis. Curr Opin Infect Dis. 2009 Oct;22(5):490-6.

18 Anand BS, Schneider FE, El-Zaatari FA, Shawar RM, Clarridge JE, Graham DY. Diagnosis of intestinal tuberculosis by polymerase chain reaction on endoscopic biopsy specimens. Am J Gastroenterol. 1994 Dec;89(12):2248-9.

19 Jullien S, Jain S, Ryan H, Ahuja V. Six-month therapy for abdominal tuberculosis. Cochrane Database Syst Rev. 2016 Nov;11:CD012163.

20 Makharia GK, Ghoshal UC, Ramakrishna BS, Agnihotri A, Ahuja V, Chowdhury SD, et al. Intermittent Directly Observed Therapy for Abdominal Tuberculosis: A Multicenter Randomized Controlled Trial Comparing 6 Months Versus 9 Months of Therapy. Clin Infect Dis. 2015 Sep;61(5):750-7. 
Case Reports in Gastroenterology
Case Rep Gastroenterol 2021;15:418-423

DOI: $10.1159 / 000514892$

(c) 2021 The Author(s). Published by S. Karger AG, Basel www.karger.com/crg

Mehershahi et al.: Abdominal Ascites of Unknown Origin: Diagnostic Accuracy of Adenosine Deaminase for Tuberculous Peritonitis

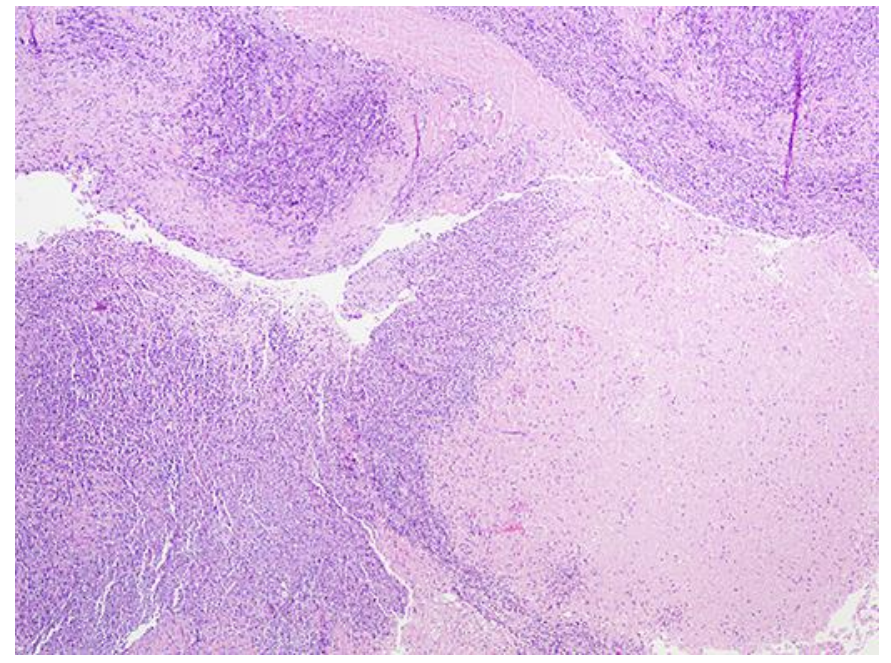

Fig. 1. Histological examination of peritoneum sample. Magnification $\times 10$. Multiple necrotizing granulomas composed of central zone of necrosis/fibrinous, surrounded by epithelioid cells and lymphocytes. 